\title{
Asymmetric Synthesis of 1-Aza-4-deoxypicropodophyllotoxin
}

\author{
Benoit M. Aigret, Jeroen Jacobs, Luc Van Meervelt, Wim M. De Borggraeve* \\ Department of Chemistry, KU Leuven, Celestijnenlaan 200F, 3001 Heverlee, Belgium \\ Fax +32(16)327990; E-mail: Wim.DeBorggraeve@chem.kuleuven.be \\ Received: 10.02.2013; Accepted after revision: 25.03.2013
}

\begin{abstract}
In our search for new easily accessible analogues based on the natural product podophyllotoxin, we synthesized 1-aza-4-deoxypicropodophyllotoxin in good overall yield and excellent enantioselectivity. The synthesis was centered around a direct asymmetric Mannich reaction using D-proline as the key step for introduction of the chiral centres. Our synthesis of 1-aza-4-deoxypodophyllotoxin was hindered through the increased instability towards epimerization of the $\mathrm{C} 2$ position. We did, however, synthesized a new scaffold based on the opened lactone analogue.
\end{abstract}

Key words: Mannich bases, asymmetric catalysis, amino aldehydes, enantioselectivity, total synthesis

4-Deoxypodophyllotoxin (DPT, 1) is a naturally occurring lignan, which was first isolated from Anthriscus sylvestris. ${ }^{1}$ It is closely related to the better known podophyllotoxin (3) that is used for the production of the anticancer drugs etoposide and teniposide (Figure 1). ${ }^{2}$ Also DPT has shown potent cytotoxicity against a series of tumor-cell lines. ${ }^{3}$ It induces cell-cycle arrest through tubulin polymerase inhibition, ${ }^{4}$ which is complementary to the topoisomerase inhibitory activity of etoposide and teniposide. Furthermore, it shows a broad spectrum of other biological activities. ${ }^{5}$

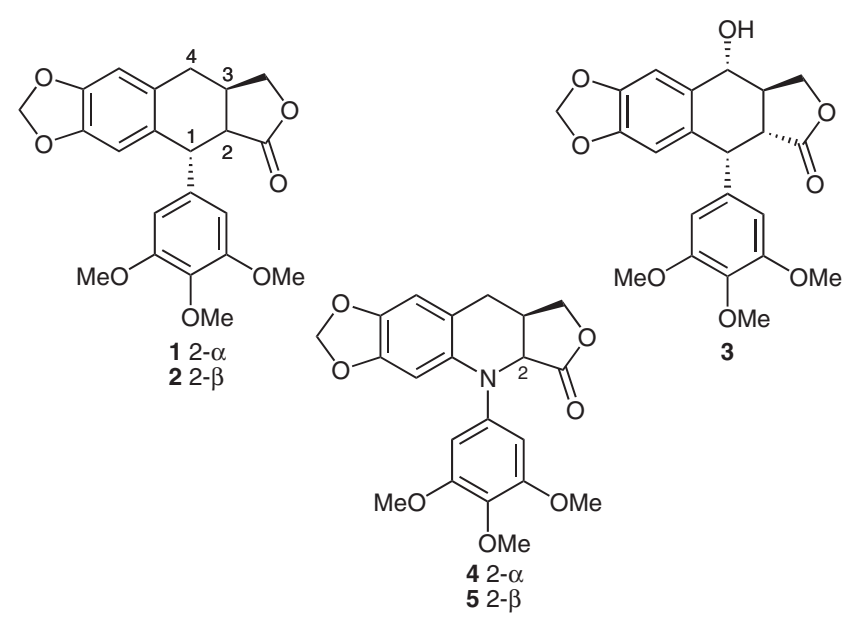

Figure 1 Structures of (deoxy)(picro)podophyllotoxin and the proposed aza analogues thereof

4-Deoxypicropodophyllotoxin (DPPT, 2, Figure 1) shows less toxicity as it is not a good inhibitor of tubulin poly-

SYNLETT 2013, 24, 1097-1100

Advanced online publication: 12.04 .2013

DOI: 10.1055/s-0033-1338414; Art ID: ST-2013-B0132-L

(C) Georg Thieme Verlag Stuttgart · New York merase. It does, however, possess immunosuppressive and anti-inflammatory properties in vitro, ${ }^{6}$ and therefore could be used as a starting point for the development of immunomodulating agents with therapeutic relevance. It is clear that the basic skeleton of podophyllotoxin can be seen as a privileged scaffold with potential applications in many fields of medicine.

Several aza analogues have been synthesized in order to find new potent antineoplasic agents with lower toxicity and improved stability. ${ }^{7}$ Most noteworthy are those based on 4-aza-2,3-didehydropodophyllotoxin, a scaffold that has retained much of the cytotoxicity of the parent compound but which is much more accessible for SAR studies due to its simplified structure and absence of the labile $\mathrm{C} 2$ stereocenter. ${ }^{8}$ Their synthesis can be performed in a single step with the use of a multicomponent reaction. ${ }^{9}$

We envisaged the synthesis of new D(P)PT analogues, more specifically 1-aza-substituted $\mathrm{D}(\mathrm{P}) \mathrm{PT}$ derivatives. Our original goal was to synthesize 1-aza-DPT (4) from which 1-aza-DPPT (5) could easily be synthesized by a base-induced epimerization of the 2-position, as this is the thermodynamically more stable cis-fused product. Central to our reaction strategy is the direct organocatalytic asymmetric Mannich reaction of an unmodified aldehyde as first reported by Barbas. ${ }^{10}$ Herein, D-proline acts as the chiral auxiliary that controls the formation of the two contiguous stereocenters upon carbon-carbon bond formation between a preformed imine and an unmodified aldehyde precursor.

In order to synthesize the aldehyde precursor, a six-step reaction sequence was optimized starting from commercially available piperonal (6, Scheme 1). Condensation with malonic acid following a literature procedure ${ }^{11}$ gave the cinnamic acid 7 in excellent yield. This was converted into the corresponding cinnamic ester $\mathbf{8}$ by refluxing in acidic methanol. Subsequent catalytic reduction with $10 \%$ $\mathrm{Pd} / \mathrm{C}$ gave the propionic ester 9, which was regioselectively brominated in dichloromethane at $0^{\circ} \mathrm{C}$ in excellent yield. The thus obtained ester $\mathbf{1 0}$ was reduced in high yield to the corresponding alcohol 11 with the use of lithium aluminium hydride at $0{ }^{\circ} \mathrm{C}$. Earlier attempts avoiding the extra esterification step led to much lower yields in this reduction step due to solubility problems of the acid in ethereal solvents (64\% vs. $97 \%)$. Up to this point, all the reactions are high yielding and do not need any additional purification after workup. Furthermore, the reactions are easily adapted to large-scale synthesis. The alcohol $\mathbf{1 1}$ was finally converted into the aldehyde $\mathbf{1 2}$ in 
good yield by the classical Swern oxidation protocol using oxalyl chloride and DMSO. ${ }^{12}$

The imine 14 was synthesized starting from 3,4,5-trimethoxyaniline (13) which was condensed with ethyl glyoxylate using an adaptation of a literature procedure and is also depicted in Scheme 1. ${ }^{13}$

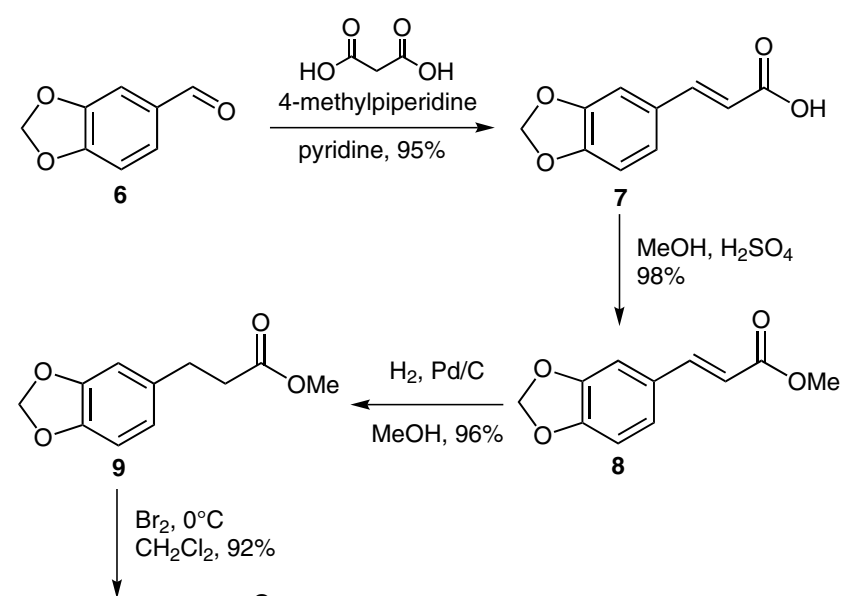<smiles>COC(=O)CCc1cc2c(cc1Br)OCO2</smiles>

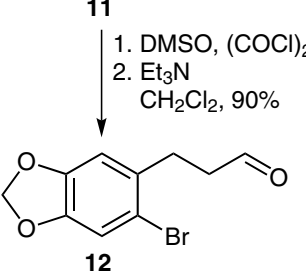<smiles>COc1cc(N)cc(OC)c1OC</smiles><smiles>CCOC(=O)C=O</smiles><smiles>CCOC(=O)/C=N/c1cc(OC)c(OC)c(OC)c1</smiles>

Scheme 1 Synthesis of the aldehyde and imine precursors

The thus formed achiral precursors where combined in an asymmetric Mannich reaction. Both aldehyde 12 and imine 14 were dissolved in THF and placed in a cryostat at $4{ }^{\circ} \mathrm{C}$. D-Proline $(30 \mathrm{~mol} \%)^{14}$ was added as the chiral catalyst, and the reaction was stirred for 16 hours at $4{ }^{\circ} \mathrm{C}$, after which the temperature was lowered to $0{ }^{\circ} \mathrm{C}$ and three equivalents of sodium borohydride were added to the reaction mixture, to reduce the aldehyde moiety in situ. ${ }^{15}$ The partial intramolecular ring closure of the thus obtained alcohol with the ester to afford lactone $\mathbf{1 6}$ was driven to completion by treatment with zinc chloride, and the product was isolated in a yield of $79 \%$ (Scheme 2 ). The stereoselectivity of the reaction was monitored by chiral HPLC using a Chiralpak-IB column. The enantiomeric ratio was found to be 99:1 and the diasteromeric ratio 95:5, showing that the presence of two extra methoxy groups compared to the more frequently employed 4-methoxy- phenyl-derived imines does not have a negative influence on the stereoselectivity of the reaction. This in contrast to 2-methoxy substituents, which gave a very low enantiomeric excess $($ ee $<10 \%)$ under these conditions. ${ }^{16}$

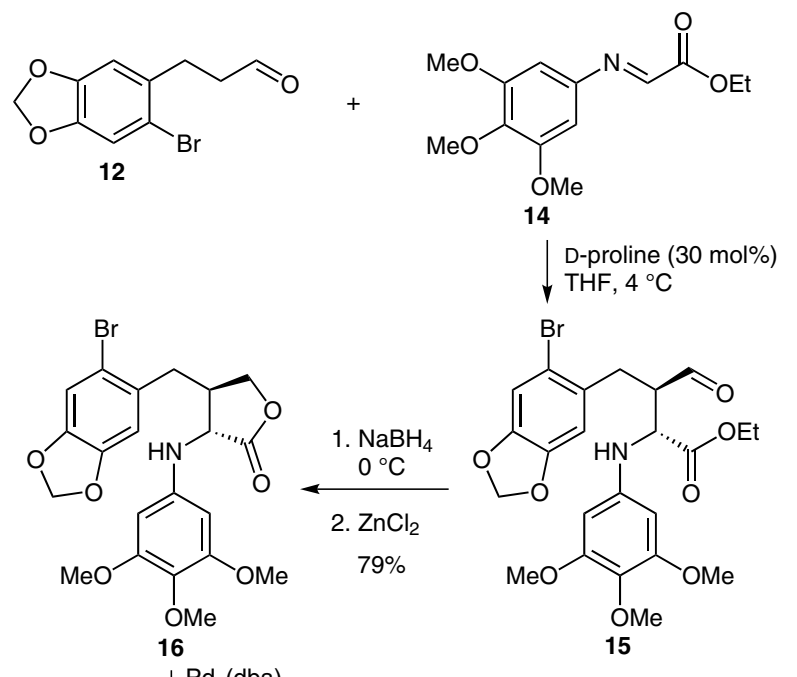
16 $\mathrm{Pd}_{2}(\mathrm{dba})_{3}$ Sphos $\mathrm{Cs}_{2} \mathrm{CO}_{3}$ toluene, $80^{\circ} \mathrm{C}$ $\checkmark 51 \%$<smiles>COc1cc(N2c3cc4c(cc3CC3COC(=O)C32)OCO4)cc(OC)c1OC</smiles>

Scheme 2 Synthesis of 1-aza-4-deoxypicropodophyllotoxin

Ring closure to the tetracyclic ring system was accomplished in moderate yield using a Buchwald-Hartwig cross-coupling reaction employing $\mathrm{Pd}_{2}(\mathrm{dba})_{3}$ as palladium source and Sphos as a ligand (Scheme 2). Other ligands such as Xphos, Ruphos, Brettphos, and $t$-BuXphos gave lower yields. ${ }^{17}$ Copper-catalyzed reactions also gave very low yields. ${ }^{18}$ Even when using $\mathrm{Cs}_{2} \mathrm{CO}_{3}$ as a base, epimerization of the chiral center next to the ester moiety could not be avoided, and the product of this reaction was 1-aza-4-deoxypicropodophyllotoxin (5), which was confirmed by X-ray crystallography (Figure 2).

Gensler reported in his original synthesis of podophyllotoxin that picropodophyllotoxin could be partially epimerized through the enolization of the ester with triphenylmethyl sodium and subsequent quench with $\mathrm{AcOH}$ at $-78{ }^{\circ} \mathrm{C}$. ${ }^{19}$ This gave him up to $38 \%$ of the desired product. When we performed a similar experiment using LDA as the base, no epimerized product could be detected upon reprotonation with $\mathrm{AcOH} .^{20}$ The different cation could not have been the source of this difference, as LDA was also used by Kende et al. in their epimerization of picropodophyllotoxin. ${ }^{21}$ 


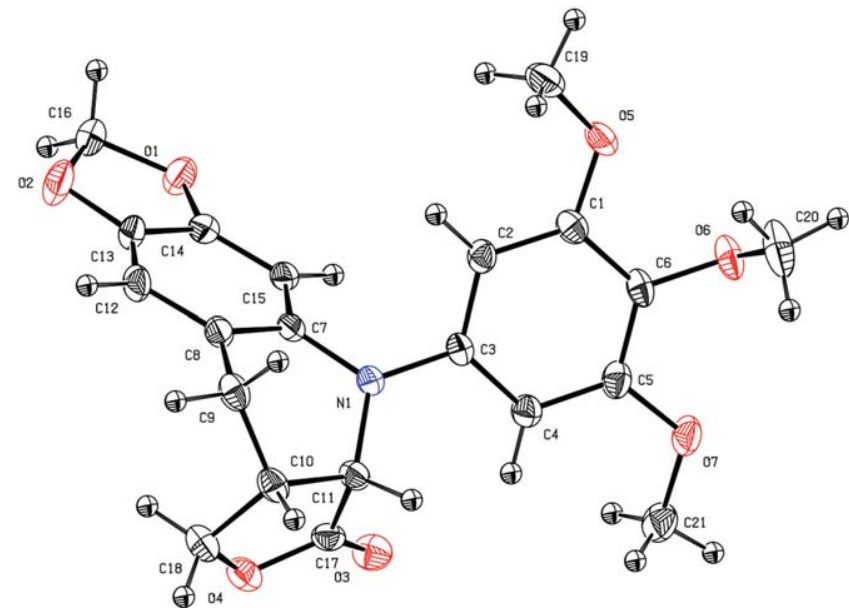

Figure 2 X-ray structure of 1 -aza-DPPT ( $50 \%$ probability of the thermal ellipsoids)

In order to avoid the epimerization occurring during the Buchwald-Hartwig ring closure, which is probably due to the high strain present in the trans-fused lactone, we chose to delay the ring closure of the lactone until after the $\mathrm{Bu}-$ chwald-Hartwig cross-coupling, as to avoid the presence of a base when working with the strained system. A strategy was thus needed to protect the alcohol in situ after the reduction of the aldehyde, to avoid any lactonization. A literature procedure using pyridinium zinc borohydride reduction in the presence of ethyl acetate to generate the acylated alcohol was tried with good results on a model system, ${ }^{22}$ but this strategy gave poor results when incorporated into our Mannich reaction. Although no literature report had been made on a consecutive reduction-silylation reaction, we thought that the intermediate alkoxyborate formed after a sodium borohydride reduction would be reactive enough to generate a silyl ether when quenched with a silyl electrophile.

Therefore, after the reduction step of the Mannich reaction, the reaction was quenched by the addition of TBSCl and imidazole to avoid any spontaneous cyclization to the lactone. This gave the TBS-protected alcohol 17 with only slightly diminished yield of $71 \%$ (er $=98: 2)$ compared to the synthesis of lactone $\mathbf{1 6}$ and is presented in Scheme 3.

The TBS-protected alcohol 17 could be cyclized using the same Buchwald-Hartwig amination protocol except that in this case Xphos proved to be the best ligand, giving product $\mathbf{1 8}$ in $61 \%$ yield (Scheme 3).

Removal of the TBS protecting group of $\mathbf{1 8}$ was done in neutral conditions using TBAF in a phosphate buffer. Deprotection proceeded smoothly when at least one equivalent of TBAF was used. We could not get complete conversion when performing the reaction using substoichiometric amounts of TBAF, as stated in the original article. ${ }^{23}$ After workup this gave the ethyl ester 19 in $74 \%$ yield (Scheme 4).

Ring closure to the trans-fused lactone did not proceed as expected. When the ester $\mathbf{1 9}$ was refluxed in THF in the

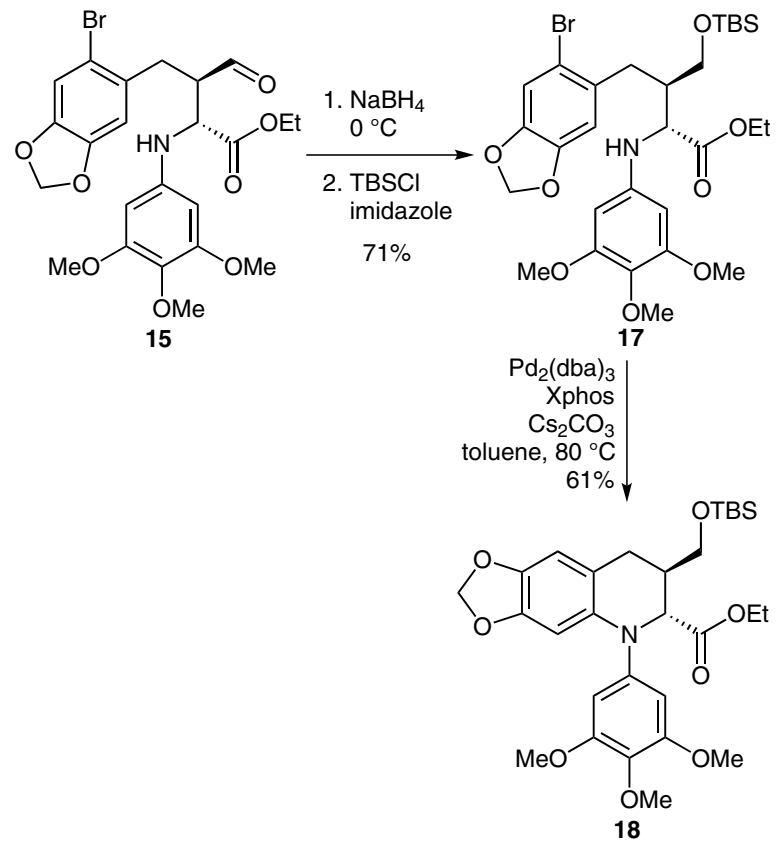

Scheme 3 In situ TBS protection and subsequent ring closure<smiles>CCCCOCC1Cc2cc3c(cc2N(c2cc(OC)c(OC)c(OC)c2)[C@H]1C(=O)OCC)OCO3</smiles><smiles>CCOC(=O)[C@H]1[C@@H](CO)Cc2cc3c(cc2N1c1cc(OC)c(OC)c(OC)c1)OCO3</smiles>

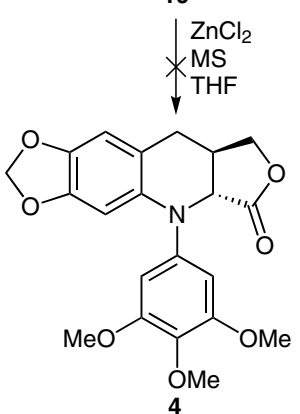

Scheme 4 TBS deprotection and attempted cyclization

presence of $\mathrm{ZnCl}_{2}$ and $4 \AA$ molecular sieves, almost no reaction took place after 24 hours (Scheme 4). When heating was continued for several days, eventually the C2epimerized cis-fused lactone $\mathbf{5}$ was again formed. This method was, however, already used successfully as the final step of the total synthesis of podophyllotoxin reported by Bush et al. ${ }^{24}$ Together with the epimerization occurring during the Buchwald-Hartwig reaction, these result shows that the 1-aza analogue of DPPT (5) is more unstable towards epimerization then DPPT (2) itself. When we attempted to hydrolyze the ester in order to cyclize it using a coupling reagent, $\mathbf{1 9}$ did not hydrolyze after refluxing in 
$1 \mathrm{M} \mathrm{HCl}$ for 24 hours. After 48 hours the product had decomposed.

Although its presence generally results in an increased activity, the lactone ring is not a prerequisite for biological activity, ${ }^{25}$ so we envisaged continuing with compound 19 as the basis for further studies as the alcohol and ester groups allow many possibilities of derivatization for further SAR studies.

To conclude we have shown a straightforward synthesis towards a new 1-aza-substituted scaffold of DPPT (5). During our search for a synthesis of 1-aza-DPT (4) we were faced with epimerization problems that could not be overcome. We have therefore shifted our attention towards 1-aza-DPPT (5) and the 1-aza analogues of the ester 19. Derivatization of these new scaffolds and broad screening of their biological activities is currently in progress and will be reported in due time. We have also shown a novel reduction-silylation strategy which might encourage more research towards examining the scope of this reaction.

\section{Acknowledgment}

This study was supported by the IWT Flanders and KU Leuven via OT/11/047.

Supporting Information for this article is available online at http://www.thieme-connect.com/ejournals/toc/synlett.

\section{References and Notes}

(1) Noguchi, T.; Kawanami, M. Yakugaku Zasshi 1940, 60, 629.

(2) Keller-Juslen, C.; Kuhn, M.; Von Wartburg, A.; Stähelin, H. J. Med. Chem. 1971, 14, 936.

(3) (a) Ikeda, R.; Nagao, T.; Okabe, H.; Nakano, Y.; Matsunaga, H.; Katano, M.; Mori, M. Chem. Pharm. Bull. 1998, 46, 871. (b) Subrahmanyam, D.; Renuka, B.; Kumar, G. S.; Vandana, V.; Deevi, D. S. Bioorg. Med. Chem. Lett. 1999, 9, 2131. (c) Kim, Y.; Kim, S. B.; You, Y. J.; Ahn, B. Z. Planta Med. 2002, 68, 271. (d) Masuda, T.; Oyama, Y.; Yonemori, S.; Takeda, Y.; Yamazaki, Y.; Mizuguchi, S.; Nakata, M.; Tanaka, T.; Chikahisa, L.; Inabak, Y.; Okada, Y. Phytother. Res. 2002, 16, 353. (e) Muto, N.; Tomokuni, T.; Haramoto, M.; Tatemoto, H.; Nakanishi, T.; Inatomi, Y.; Murata, H.; Inada, A. Biosci., Biotechnol., Biochem. 2008, 72, 477.

(4) (a) Gupta, R. S. Cancer Res. 1983, 43, 505. (b) Loike, J. D. Cancer Res. 1978, 38, 2688. (c) Suh, S. J.; Kim, J. R.; Jin, U. H.; Choi, H. S.; Chang, Y. C.; Lee, Y. C.; Kim, S. H.; Lee, I. S.; Moon, T. S.; Chang, H. W.; Kim, C. H. Vasc. Pharmacol. 2009, 51, 13. (d) Yong, Y. J.; Shin, S. Y.; Lee, Y. H.; Lim, Y. H. Bioorg. Med. Chem. Lett. 2009, 19, 4367. (e) Shin, S. Y.; Yong, Y.; Kim, C. G.; Lee, Y. H.; Lim, Y. Cancer Lett. 2010, 287, 231.

(5) (a) Sudo, K.; Konno, K.; Shigeta, S.; Yokota, T. Antiviral Chem. Chemother. 1998, 9, 263. (b) Ikeda, R.; Nagao, T.; Okabe, H.; Nakano, Y.; Matsunaga, H.; Katano, M.; Mori, M. Chem. Pharm. Bull. 1998, 46, 871. (c) Chen, J. J.; Chang, Y. L.; Teng, C. M.; Chen, I. S. Planta Med. 2000, 66, 251. (d) Lin, C. X.; Lee, E.; Jin, M. H.; Yook, J.; Quan, Z.; Ha, K.; Moon, T. C.; Kim, M. J.; Kim, K. J.; Lee, S. H.; Chang, H. W. Planta. Med. 2006, 72, 786. (e) Lee, S. H.; Son, M. J.;
Ju, H. K.; Lin, C. X.; Moon, T. C.; Choi, H. G.; Son, J. K.; Chang, H. W. Biol. Pharm. Bull. 2004, 27, 786. (f) Lin, C. X.; Son, M. J.; Ju, H. K.; Moon, T. C.; Lee, E.; Kim, S. H.; Kim, M. J.; Son, J. K.; Lee, S. H.; Chang, H. W. Planta. Med. 2004, 70, 474. (g) Inamori, Y.; Kato, Y.; Kubo, M.; Baba, K.; Ishida, T.; Nomoto, K.; Kozawa, M. Chem. Pharm. Bull. 1985, 33, 704.

(6) Axelson, M.; Larsson, O. WO 2009/157858 A1, 2009.

(7) Kumar, A.; Kumar, V.; Alegria, A. E.; Malhotra, S. V. Curr. Med. Chem. 2011, 18, 3853.

(8) (a) Hitotsuyanagi, Y.; Kobayashi, M.; Fukuyo, M.; Takeya, K.; Itokawa, H. Tetrahedron Lett. 1997, 39, 8295. (b) Hitotsuyanagi, Y.; Fukuyo, M.; Tsuda, K.; Kobayashi, M.; Ozeki, A.; Itokawa, H.; Takeya, K. Bioorg. Med. Chem. Lett. 2000, 10, 315.

(9) Tratat, C.; Giorgi-Renault, S.; Husson, H. P. Org. Lett. 2002 , 4, 3187.

(10) (a) Notz, W.; Tanaka, F.; Watanabe, S. I. Chowdari N. S.; Turner, J. M.; Thayumanavan, R.; Barbas, C. F. III. J. Org. Chem. 2003, 68, 9624. For more recent examples concerning this reaction, see: (b) Uchida, T.; Rodriquez, M.; Schreiber, S. L. Org. Lett. 2009, 11, 1559. (c) Zhao, G.-L.; Córdova, A. Tetrahedron Lett. 2006, 42, 7417. (d) Watanabe, S.-I.; Córdova, A.; Tanaka, F.; Barbas, C. F. III. Org. Lett. 2002, 4, 4519. (e) Martin-Rapún, R.; Fan, X.; Sayalero, S.; Bahramnejad, M.; Cuevas, F.; Pericàs, M. A. Chem. Eur. J. 2011, 17, 8780. (f) Chowdari, N. S.; Suri, J. T.; Barbas, C. F. III. Org. Lett. 2004, 6, 2507.

(11) Ferreira, W. S.; Freire-de-Lima, L.; Saraiva, V. B.; AlissonSilva, F.; Mendonca-Previato, L.; Previato, J. O.; Echevarria, A.; Freire de Lima, M. E. Bioorg. Med. Chem. 2008, 16, 2984.

(12) Omura, K.; Swern, D. Tetrahedron 1978, 34, 1651.

(13) Borrione, E.; Prato, M.; Scorrano, G.; Stivanello, M.; Lucchini, V. J. Heterocycl. Chem. 1988, 25, 1831.

(14) Lower catalyst loading led to a lower enantioselectivity, $10 \%$ catalyst loading gave $72 \%$ ee, $20 \%$ catalyst loading gave $88 \%$ ee.

(15) This lower temperature is necessary to avoid epimerization of the $\alpha$-carbon next to the aldehyde during the reduction.

(16) List, B.; Pojarliev, P.; Biller, W. T.; Martin, H. J. J. Am. Chem. Soc. 2002, 124, 827.

(17) Yields obtained for other ligands; Xphos: 39\%, Ruphos: $42 \%$, Brettphos: $21 \%, t$-BuXphos: $14 \%$.

(18) Yields for copper reactions using $\mathrm{CuI}$ with ligand: TMEDA: $9 \%$, 4-hydroxyproline: $12 \%$.

(19) Gensler, W. J.; Gatsonis, C. D. J. Org. Chem. 1966, 31, 4004.

(20) Triphenylmethylsodium is an unstable reagent and is therefore not commercially available. We were unable to prepare the reagent due to safety regulations of our department concerning the use of mercury. For the synthesis of triphenylmethylsodium, see: Renfrow, W. B. Jr.; Hauser, C. R. Org. Synth. 1943, 2, 607.

(21) Kende, A. S.; King, M. L.; Curran, D. P. J. Org. Chem. 1981, 46, 2826.

(22) Zeynizadeh, B.; Faraji, F. Bull. Korean Chem. Soc. 2008, 29, 76.

(23) DiLauro, M.; Seo, W.; Phillips, S. T. J. Org. Chem. 2011, 76, 7352.

(24) Bush, E. J.; Jones, D. W. J. Chem. Soc., Chem. Commun. 1993, 1200.

(25) Subrahmanyam, D.; Renuka, B.; Rao, C. V. L.; Sagar, P. S.; Deevi, D. S.; Babu, J. M.; Vyas, K. Bioorg. Med. Chem. Lett. 1998, 8, 1391. 